\title{
Evaluation of Performance Wastewater Treatment Plants in Tehran, Iran
}

\author{
Alireza Mesdaghinia, Amirabbas Hamedian and Kourosh Rahmani \\ Department of Enviromental Health, School of Health, \\ Tehran Uniuversity of Medical Sciences, Tehran, Iran
}

\begin{abstract}
In attention to healthy risks of effluent discharge of wastewater from treatment plants to water sources and use in agriculture, this study was carried out for quality assessment of effluent discharge from Tehran wastewater treatment plant Tehran, Iran in 2010. For this investigation, according to Iranian EPA standard's procedure, the mixing sampling method was carried out from effluent $>24 \mathrm{~h}$ and some of physical and chemical characteristics of sample measured by standard methods. TS and TSS had been minimum and maximum removal, respectively ( 35 and $97 \%$ ). TS of the outgoing wastewater in all plants exceed the standard rate and the rate of $\mathrm{COD}, \mathrm{BOD}$ and phosphorus in the outgoing wastewater is mild and fall within the range defined by Department of Environment and WHO.
\end{abstract}

Key words: Healthy risks, effluent, discharge, wastewater, treatment plants, Iran

\section{INTRODUCTION}

During the years of 1980 s and 1990 s with great leaps forward in the technology of wastewater treatment, improvement of this technology considered as proper solution in achieving a higher quality of services by the wastewater treatment plants. Results of the research in the field have been published in journals such as Water Science and Technology (Bu et al., 1994; Qasim, 1999; WEF, 2005; Mahvi et al., 2006). In another study by Colmenarejo et al. (2006)'s investigation of the wastewater treatment plants of the wastewater in Madrid, Spain, using different methods, the efficiency of the different procedures of refining has been examined, having in its centre and comparison of the removal rate of the waste material (Colmenarejo et al., 2006). Some other studies have been carried out for improvement of the service quality of the wastewater treatment plants which are as follows:

Improvement of munchen wastewater treatment plant: $T_{0}$ remove nitrogen (Eichinger, 1994; Hamoda and Al-Sharekh, 1999; Hamoda and Al-Ghusain, 1998; Loukidou and Zouboulis, 2001) usage of microstraining as an advanced procedure of wastewater treatment in Wiesbaden (Grau et al., 1994), improvement of the paper mill wastewater treatment in Neifern $\mathrm{GmbH}$ using the floating bed system (Schneeberg, 1994), improvement of the Bani Saef wastewater treatment plant in Egypt to meet the overloading (Fedal, 1990), improvement of the performance of a stabilization pond in Alabama, US using a blue hyacinth (Mcanally, 1990) and improvement of the efficiency of the Kanpoor wastewater treatment plant in India to increase hydraulic capacity (Gould, 1990). In another study, the removal rate of $\mathrm{BOD}_{5}, \mathrm{COD}$ and TSS were 95, 93 and 92, respectively (Sharkawi et al., 1995). In the present study, the removal rate efficiency of the Tehran wastewater treatment plant has been examined.

\section{MATERIALS AND METHODS}

The study has been carried out in full scale and in eight household wastewater treatment plants of the city of Tehran including an investigation of the present state and its comparison to the pollutant removal criteria. In the present study, the present efficiency of the operating plants is investigated qualitatively and quantitatively. Also, the study examines the precision and accuracy rate of the results of experiments in each and every plant for samples collected for TSS, COD and BOD after and before treatment using methods described in the procedure standard (PAH, AWWA and WEF, 1998). Numeric values of the precision and accuracy are also determined. The results show that the quality of the input wastewater underwent little change which can be attributed to the use of a homogenous container tanks.

\section{RESULTS AND DISCUSSION}

In Table 1, the quality of the incoming untreated wastewater in the plants under study in the 2nd

Corresponding Author: Alireza Mesdaghinia, Department of Enviromental Health, School of Health, Tehran Uniuversity of Medical Sciences, Tehran, Iran 
Res. J. Biol. Sci., 6 (1): 30-32, 2011

Table 1: Incoming untreated wastewater in the plants under study in the 2nd 6 months of 1389 (October 2010 to March 2011)

\begin{tabular}{lrrrccc}
\hline Treatment plants & TS & TSS & COD & BOD $_{5}$ & N & p-value \\
\hline Shoosh & 1038 & 218 & 339 & 227 & 46.2 & 21.30 \\
Doulatabad & 953 & 276 & 266 & 180 & 33.0 & 15.74 \\
Jonoob & 955 & 173 & 242 & 177 & 50.7 & 14.00 \\
Mahalati & 697 & 204 & 286 & 188 & 35.3 & 15.50 \\
Sahebgharaniye & 506 & 100 & 185 & 124 & 40.0 & 10.91 \\
Zargande & 640 & 126 & 125 & 163 & 52.5 & 14.75 \\
Ghytariye & 527 & 174 & 163 & 144 & 37.0 & 13.40 \\
Shahrakegharb & 730 & 193 & 144 & 172 & 29.2 & 12.54 \\
Ekbatan & 486 & 131 & 172 & 112 & 36.2 & 12.76 \\
\hline
\end{tabular}

Table 2: Outgoing wastewater from plants in the 2nd 6 months of 1389 (October 2010 to March 2011)

\begin{tabular}{lcrrrrr}
\hline Treatment plants & TS & \multicolumn{1}{c}{ TSS } & COD & BOD $_{5}$ & \multicolumn{1}{c}{$\mathrm{N}$} & p-value \\
\hline Shoosh & 713.0 & 26.57 & 34.46 & 16.80 & 15.20 & 4.82 \\
Doulatabad & 788.0 & 36.22 & 30.43 & 18.65 & 2.00 & 5.11 \\
Jonoob & 613.0 & 10.93 & 21.66 & 9.48 & 2.67 & 5.00 \\
Mahalati & 362.2 & 13.96 & 26.46 & 12.89 & 6.07 & 4.76 \\
Sahebgharaniye & 302.0 & 9.71 & 12.78 & 8.32 & 5.34 & 3.48 \\
Zargande & 517.0 & 16.95 & 20.35 & 9.56 & 4.24 & 4.32 \\
Ghytariye & 353.3 & 4.99 & 14.13 & 6.31 & 5.97 & 3.94 \\
Shahrakegharb & 563.3 & 50.00 & 30.00 & 29.80 & 3.64 & 4.98 \\
Ekbatan & 420.0 & 8.50 & 19.50 & 29.20 & 4.40 & 4.15 \\
\hline
\end{tabular}

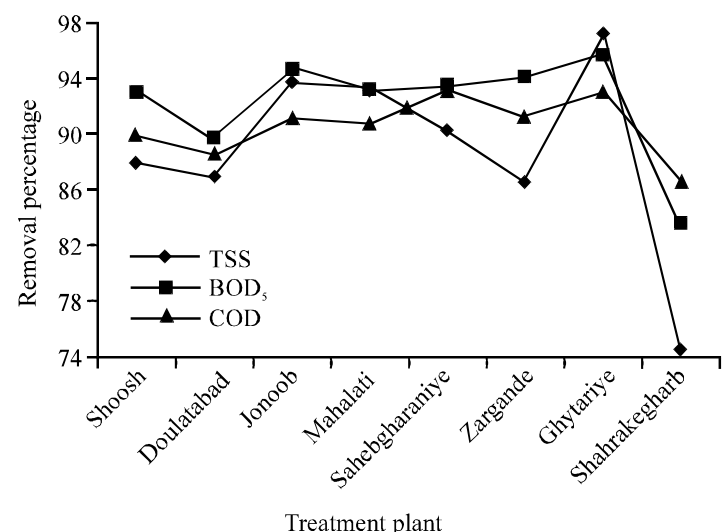

Fig. 1: Removal percentage of $\mathrm{BOD}, \mathrm{COD}$ and TSS

6 months of 1389 (October 2010 to March 2011) has been presented. Based on the collected data on the quality of incoming untreated wastewater (Table 1), it is clear that all samples of the study come under the category of moderate in the classification scale of the wastewaters. Based on the data on the ratio of BOD-COD, it is clear that the wastewaters have moderate decomposability.

In Table 2, the quality of the outgoing wastewater from plants in the 2nd 6 months of 1389 (October 2010 to March 2011) has been presented. TS of the outgoing wastewater in all plants exceed the standard rate of TS determined by the Department of Environment, alarming the poor performance of the plants in operational units and the need to solve the problems and better operation. The rate of $\mathrm{COD}, \mathrm{BOD}$ and phosphorus in the outgoing

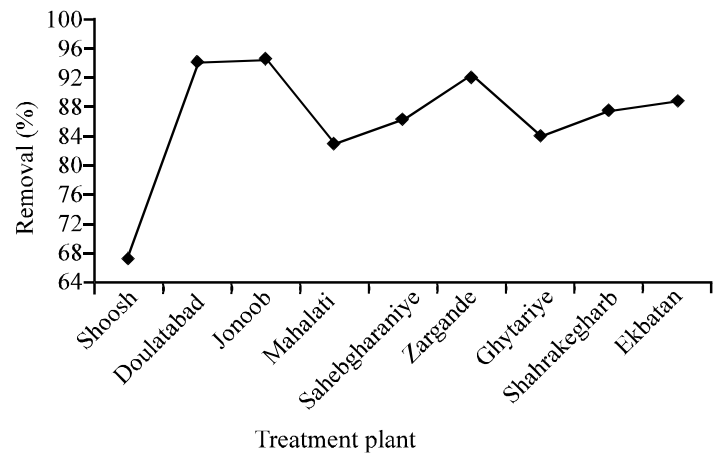

Fig. 2: Removal percentage nitrogen

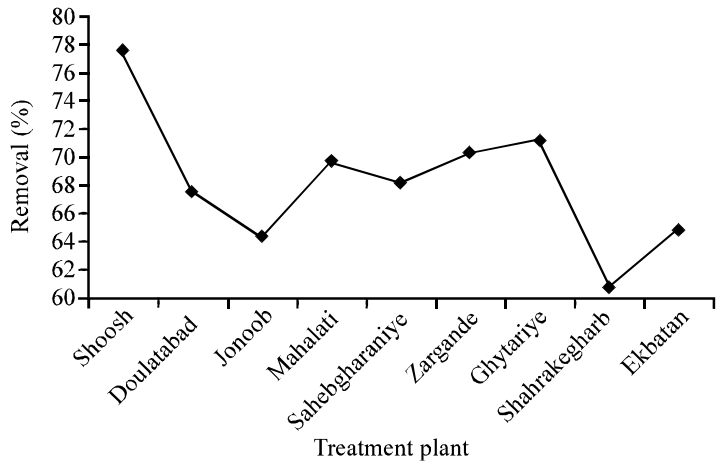

Fig. 3: Removal percentage phosphorus

wastewater is mild and fall within the range defined by Department of Environment and WHO. As shown in Fig. 1, the removal rate of $\mathrm{BOD}, \mathrm{COD}$ and TSS have been compared among wastewater treatment plants within Iran, among which Shahre Qods wastewater treatment plant show the least removal rate (Fig. 2 and 3). The efficiency of the wastewater treatment plants of the city of Tehran in removing phosphorus and nitrogen in the 1st 6 months of 1389. The results in Fig. 2 and 3 show that Soosh plant has the best removal rate of phosphorus and nitrogen and Shahre Qods plant has the worst removal rate. However, the average percentage of removal rate in all plants under study operating as advanced wastewater treatment plants is satisfactory.

\section{CONCLUSION}

Based on the results of the study, it can be concluded that the most important problem of the Tehran wastewater treatment plants is their inability in removing TSS. The most optimal and rapid solution to this problem is to use sand filtration after the normal treatment in order to keep the rate of TSS within the range of standards set by the Department of Environment. However, using growth reactors in the treatment ponds would help in improving the removal rate and solve the problem of the suspension growth in the Tehran plants. 


\section{REFERENCES}

Bu, S., J. Einfeldt, H. Gunter and T. Werner, 1994. Upgrading of wastewater treatment plants to achieve advanced standards concerning nutrient removal. Water Sci. Tech., 29: 49-58.

Colmenarejo, M.F., A. Rubio, E. Sanchez, J. Vicente, M.G. Garcia and R. Borja, 2006. Evaluation of municipal wastewater treatment plants with different technologies at Las Rozas, Madrid (Spain). J. Environ. Manage., 81: 399-404.

Eichinger, J., 1994. Upgrading of munich wastewater treatment plant to nitrogen removal. Water Sci. Tech., 29: $217-225$.

Fedal, A., 1990. Rehabilitation and upgrading of the benisuef city wastewater treatment plant. Water Sci. Tech., 22: 131-138.

Gould, D.F.J., 1990. Upgrading of the treatment plants using pure oxygen. Water Sci. Tech., 22: 301-302.

Grau, A., M. Haeusler and W. Schmitt, 1994. Use of microstraining as advanced treatment in main WWTP of wisbaden. Water Sci. Tech., 29: 237-245.

Hamoda, M.F. and H.A. Al-Sharekh, 1999. Sugar wastewater treatment with aerated fixed-film biological systems. Water Sci. Technol., 40: 313-321.

Hamoda, M.F. and I.A. Al-Ghusain, 1998. Analysis of organisc removal rates in the aerated submerged fixed film process. Water Sci. Technol., 38: 213-221.
Loukidou, M.X. and A.I. Zouboulis, 2001. Comparison of two biological treatment processes using attached-growth biomass for sanitary landfill leachate treatment. Environ. Pollut., 111: 273-281.

Mahvi, A.H., Y. Rahimi and A.R. Mesdaghinia, 2006. Assessment and upgrading of khoy wastewater treatment plant. Pak. J. Biol. Sci., 9: 1276-1281.

Mcanally, A.S., 1990. Use of constructed water hyanith treatment systens to upgrading small flow municipal wastewater treatment facilities. J. Environ. Sci. Health Part-A, 27: 903-927.

PAH, AWWA and WEF, 1998. Standard Methods for the Examination of Water and Wastewater. 20th Edn., United Book Press, Baltimore.

Qasim, S.R., 1999. Wastewater Treatment Plants, Planning, Design and Operation. 2nd Edn., Technomic Publishing Co., Lanchester, PA.

Schneeberg, E., 1994. Upgrading of niefern gmbh paper mill in germany using the floating bed. Water Sci. Tech., 29: 177-183.

Sharkawi, F.E.L., O. Sebaie, A. Hossam and G. Abdel Kerim, 1995. Evaluation of dagahla wastewate treatment plant, aerated lagoon and sysetem. J. Water Sei. Technol., 32: 111-111.

WEF, 2005. Upgrading and Retrofitting Water and Wastewater Treatment Plants. McGraw-Hill, New York, pp: 2-8. 